\title{
Feed intake is related to changes in plasma nonesterified fatty acid concentration and hepatic acetyl CoA content following feeding in lactating dairy cows
}

\author{
P. Piantoni, C. M. Ylioja, and M. S. Allen ${ }^{1}$ \\ Department of Animal Science, Michigan State University, East Lansing 48824
}

\begin{abstract}
The relationship between hepatic acetyl CoA (AcCoA) content and dry matter intake (DMI) was evaluated using 28 multiparous Holstein cows; 14 were early postpartum (PP; $12.6 \pm 3.8 \mathrm{~d}$ in milk) and 14 were late-lactation cows (LL; $269 \pm 30 \mathrm{~d}$ in milk). Cows were fed once daily, and DMI was determined for the first 4 $\mathrm{h}$ after feeding. Liver and blood samples were collected before feeding and $4 \mathrm{~h}$ after feeding. Feed intake over the 4-h period ranged from 3.7 to $9.6 \mathrm{~kg}$ of dry matter and was similar for the 2 stages of lactation. Before feeding, hepatic AcCoA content was greater for PP compared with LL cows (34.4 vs. $12.5 \mathrm{nmol} / \mathrm{g}$ ), and decreased over the $4 \mathrm{~h}$ after feeding for PP only (28.7 vs. $34.4 \mathrm{nmol} / \mathrm{g}$ ). The range for change in $\mathrm{AcCoA}$ over the 4-h period was wide for both PP $(-24.3$ to 10.4 $\mathrm{nmol} / \mathrm{g}$ ) and LL ( -5.7 to $16.1 \mathrm{nmol} / \mathrm{g})$, and was related negatively to DMI at $4 \mathrm{~h}$ for both $\mathrm{PP}\left(\mathrm{R}^{2}=0.55\right)$ and LL $\left(\mathrm{R}^{2}=0.31\right)$. The reduction in plasma NEFA concentration over the 4-h period was greater for PP than LL cows ( -681 vs. $-47 \mu \mathrm{Eq} / \mathrm{L})$, and was related to DMI at $4 \mathrm{~h}$ for both PP and LL (both $\mathrm{R}^{2}=0.38$ ). Greater DMI among cows over the first $4 \mathrm{~h}$ after feeding might have been from a sharper reduction in supply of AcCoA in the liver for oxidation during meals because of the reduction in plasma NEFA concentration. Consistent with this is that the change in AcCoA was positively related to the reduction in plasma NEFA concentration for PP cows $\left(\mathrm{R}^{2}=0.31\right)$. However, change in plasma NEFA concentration was not related to change in hepatic AcCoA in LL cows, indicating that the pool of AcCoA in LL cows is not as dependent on NEFA flux to the liver as that of PP cows. Further research is required to determine production and fate of $\mathrm{AcCoA}$ within the timeframe of meals and the effects of feeding on energy charge in hepatic tissue.
\end{abstract}

Received November 7, 2014.

Accepted May 14, 2015.

${ }^{1}$ Corresponding author: allenm@msu.edu
Key words: acetyl CoA, late lactation, metabolic control of intake, nonesterified fatty acid, postpartum

\section{INTRODUCTION}

Various fuels including FA, lactate, and AA enter the tricarboxylic acid cycle for oxidation through acetyl CoA (AcCoA). Hepatic content of AcCoA is elevated during the lipolytic state when flux of NEFA to the liver and $\beta$-oxidation increase greatly (Reynolds et al., 2003). During a meal, anapleurosis of the tricarboxylic acid cycle in hepatocytes will increase oxidation of AcCoA, generating reducing equivalents and $\mathrm{CO}_{2}$, and increasing ATP production, possibly decreasing feed intake (Allen and Piantoni, 2013). Propionate enters the tricarboxylic acid cycle through succinyl $\mathrm{CoA}$ and is considered a primary anapleurotic metabolite, especially during meals (Allen et al., 2009). The hypophagic effects of propionate infusions have been associated with the size of the existing pool of hepatic AcCoA among early-lactation cows (Stocks and Allen, 2012, 2013). Stocks and Allen (2012) showed that the decrease in DMI observed with propionic acid infusions was positively related to hepatic AcCoA content in early-postpartum cows. In addition, it was shown in a later study that propionic acid infusions decreased DMI in postpartum dairy cows but only over the first $4 \mathrm{~h}$ after feeding and not the remaining $20 \mathrm{~h}$, and more so in cows with higher hepatic AcCoA content (Stocks and Allen, 2013). Because propionate flux to the liver increases dramatically within the time frame of meals (Benson et al., 2002), its central role for stimulating satiety in dairy cattle by increasing oxidation of AcCoA in the tricarboxylic acid cycle has been suggested (Allen, 2000; Allen et al., 2005). Moreover, Oba and Allen (2003) showed that intraruminal infusions of propionate were more hypophagic in early- than in mid-lactation cows. Because late-lactation cows are not in a lipolytic state, their hepatic pool of AcCoA is not expected to be large, and therefore, control of intake in these cows might be less affected by propionate flux to the liver compared with early-lactation cows. 
Extensive research in laboratory animals supports the theory that oxidation of fuels in the liver affects feed intake (Friedman et al., 1986), and this mechanism has been proposed to be conserved in ruminants (Allen et al., 2005). Fuels that can be extracted from the blood and oxidized in the ruminant liver include propionate, butyrate, NEFA, AA, glycerol, and lactate. Fuels are oxidized in the tricarboxylic acid cycle, generating $\mathrm{CO}_{2}$ and reducing equivalents that will then feed into the oxidative phosphorylation cascade, generating ATP, and possibly increasing hepatic energy status and contributing to satiety (Allen and Piantoni, 2013). The energy status of the liver, determined by the balance between the rate of production and utilization of highenergy bonds, and not the oxidation of fuels or ATP production per se, is likely the signal that affects feed intake (Friedman, 1997; Friedman et al., 1999). During a meal, anapleurosis of the tricarboxylic acid cycle from propionate will initially be offset by catapleurosis of intermediates such as malate for glucose production until the gluconeogenic pathway is saturated. At this point, oxidation of AcCoA will increase due to increased supply of tricarboxylic acid cycle intermediates (Allen et al., 2009), likely increasing ATP production and contributing to satiety. Re-entry of tricarboxylic acid cycle intermediates into the mitochondria as pyruvate might contribute to AcCoA supply as their concentrations in the cytosol build up when the gluconeogenic pathway is saturated from continuous flux of propionate to the liver during a meal, especially for cows in late lactation with lower hepatic acetyl CoA content.

The objective of this experiment was to evaluate the relationship between hepatic AcCoA and DMI in early postpartum and late-lactation dairy cows. We hypothesized that (1) hepatic AcCoA will be higher for early postpartum than late-lactation cows, (2) hepatic AcCoA will decrease after feeding regardless of stage of lactation, and (3) a greater decrease in hepatic AcCoA will be related to lower DMI during the first $4 \mathrm{~h}$ after feeding.

\section{MATERIALS AND METHODS}

\section{Animal Housing and Care}

All experimental procedures were approved by the Institutional Animal Care and Use Committee at Michigan State University (East Lansing). All cows were housed in the same tie-stall throughout the experiment. Cows were fed once daily $(1000 \mathrm{~h})$ at $115 \%$ of expected intake and milked twice daily (0500 and $1630 \mathrm{~h})$. The amounts of feed offered and refused were weighed for each cow daily.

\section{Design and Treatment Diets}

Twenty-eight multiparous Holstein cows at the Michigan State University Dairy Field Laboratory, consisting of 14 early postpartum (PP) cows with the following characteristics: $12.6 \pm 3.8 \mathrm{DIM}, 48.5 \pm 7.9 \mathrm{~kg} 3.5 \%$ FCM, $85.8 \pm 94 \times 1,000 / \mathrm{mL}$ SCC, $2.70 \pm 0.45 \mathrm{BCS}$, and $709 \pm 42 \mathrm{~kg}$ of BW (all means $\pm \mathrm{SD}$ ), and 14 latelactation (LL) cows with the following characteristics: $269 \pm 30$ DIM, $31.4 \pm 5.9 \mathrm{~kg} 3.5 \%$ FCM, $137 \pm 96 \times$ $1,000 / \mathrm{mL} \mathrm{SCC}, 2.90 \pm 0.52 \mathrm{BCS}$, and $744 \pm 50 \mathrm{~kg}$ of BW (all means $\pm \mathrm{SD}$ ), were used in a randomized block design experiment. Cows were blocked by date of parturition of PP cows. Postpartum cows were between 3 and 14 DIM, and LL cows were over 200 DIM at the beginning of the experiment. Depending on the number of PP cows in each block, LL cows were chosen from the herd based on stable milk yield, DMI, and health. The experiment was conducted over a period of 2 mo with 3 blocks containing 6,10 , and 12 cows each. Within blocks, cows were paired by stage of lactation (each pair contained $1 \mathrm{PP}$ and 1 LL cow). No other criteria were used for the pairing, but stage of lactation and cows were randomly assigned to alternate stalls by stage of lactation. The experiment lasted $4 \mathrm{~d}$ for each block of cows: cows were adjusted to stalls for the first $3 \mathrm{~d}$ and feeding behavior was recorded and samples collected on d 4 . On d 4, feeding was staggered by pair to allow for biopsies to be performed $4 \mathrm{~h}$ after feeding. A postpartum or late-lactation diet was offered to the cows depending on their stage of lactation. The ingredient and nutrient composition of the diets fed as TMR are reported in Table 1. Diets were formulated to meet requirements according to NRC (2001).

\section{Data and Sample Collection}

Feed offered and refused was recorded throughout the experiment. However, only feed offered and refused recorded on d 4 was used for statistical analyses. Milk yield was recorded and milk samples were collected at each milking on d 4 for composition analyses. Body weight and BCS (Wildman et al., 1982) were recorded once per block. To characterize diets, a TMR sample was collected once per block.

On d 4 of the experiment, feed refused was also recorded at $4 \mathrm{~h}$ after feeding, and blood and liver samples were collected before and $4 \mathrm{~h}$ after feeding for each cow. Blood samples were collected by venipuncture of coccygeal vessels before liver biopsies into 2 evacuated tubes, one containing potassium EDTA and the other containing potassium oxalate with sodium fluoride as a glycolytic inhibitor. Both tubes were centrifuged at 
Table 1. Ingredient and nutrient composition of the diets fed to postpartum and late-lactation cows

\begin{tabular}{|c|c|c|}
\hline \multirow[b]{2}{*}{ Item } & \multicolumn{2}{|c|}{ Diet } \\
\hline & Postpartum & Late lactation \\
\hline \multicolumn{3}{|l|}{ Ingredient, $\%$ of DM } \\
\hline Corn silage & 39.6 & 34.1 \\
\hline Alfalfa silage & 20.1 & 14.5 \\
\hline Alfalfa hay & 7.83 & — \\
\hline Wheat straw & - & 3.72 \\
\hline Dry ground corn & 14.6 & 19.7 \\
\hline Corn gluten feed & - & 16.0 \\
\hline Soybean meal & 14.1 & 9.17 \\
\hline Vitamin-mineral mix ${ }^{1}$ & 3.66 & 2.80 \\
\hline \multicolumn{3}{|l|}{ Nutrient composition $^{2}$} \\
\hline $\mathrm{DM}, \%$ & 55.2 & 50.6 \\
\hline Starch, \% of DM & 24.7 & 23.7 \\
\hline NDF, \% of DM & 30.5 & 33.6 \\
\hline $\mathrm{CP}, \%$ of $\mathrm{DM}$ & 16.4 & 16.6 \\
\hline
\end{tabular}

${ }^{1}$ Vitamin-mineral mix contained (DM basis): $34.5 \%$ sodium chloride, $29.4 \%$ calcium carbonate, $13.4 \%$ magnesium oxide, $12.5 \%$ monocalcium phosphate, $5.40 \%$ soybean oil, and $4.85 \%$ trace minerals and vitamins.

${ }^{2}$ For the postpartum diet, DM SD: $\pm 3.64 \%$, starch SD: $\pm 2.44 \%$, NDF SD: $\pm 0.44 \%$, and CP SD: $\pm 1.49 \%$. For the late-lactation diet, DM SD: $\pm 3.60 \%$, starch SD: $\pm 2.38 \%$, NDF SD: $\pm 1.57 \%$, and CP SD: $\pm 1.54 \%$.

$2,000 \times g$ for 15 min after sample collection, and plasma was harvested and stored at $-20^{\circ} \mathrm{C}$ until analysis. Liver tissue was collected before and $4 \mathrm{~h}$ after feeding for each cow for determination of AcCoA content. After local anesthetization with $2 \%$ lidocaine hydrochloride, a skin incision was performed and the biopsy instrument (14-gauge Vet-Core biopsy needles, Global Veterinary Products, Seaforth, Australia) inserted between the 10th and 11th ribs on a line between the olecranon and the tuber coxae on the right side. Ten samples of $\sim 20$ mg each were collected, snap-frozen in liquid nitrogen, and stored at $-80^{\circ} \mathrm{C}$ until further processing.

\section{Sample Analysis}

Samples of TMR and orts were processed and analyzed for DM, NDF, CP, and starch contents as described in Piantoni et al. (2013). Plasma samples were analyzed in duplicate. Commercial kits were used to determine plasma concentrations of insulin (bovine insulin ELISA, \#10-1201-01, Mercodia, Uppsala, Sweden; intraassay CV: 2.6\%), NEFA [NEFA-HR (2) kit, Wako Chemicals USA Inc., Richmond, VA; intraassay CV: 2.9\%], and betahydroxybutyrate (kit no. 2240, Stanbio Laboratory, Boerne, TX; intraassay CV: 4.8\%). Plasma glucose concentration was analyzed using a glucose oxidase method (PGO Enzyme Product No. P7119, Sigma Chemical Co.; intraassay CV: 1.8\%). Liver samples were analyzed for AcCoA content as described in Stocks and Allen (2012). Liver AcCoA content is expressed per weight of wet liver.

\section{Statistical Analysis}

Changes in plasma metabolites and insulin concentrations were analyzed using PROC MIXED of SAS (SAS Institute Inc., Cary, NC) according to the following model:

$$
\begin{aligned}
Y_{j k l m n}=\mu & +B_{j}+P_{k}\left(B_{j}\right)+S_{l}+C\left(B_{j} P_{k} S_{l}\right)_{m} \\
& +T_{n}+T_{n} S_{1}+e_{j k l m n},
\end{aligned}
$$

where $Y_{j k l m n}=$ dependent variable; $\mu=$ overall mean; $\mathrm{B}_{\mathrm{j}}=$ random effect of block $(\mathrm{j}=1$ to 3$) ; \mathrm{P}_{\mathrm{k}}=$ random effect of pair within block ( $\mathrm{k}=1$ to 14$) ; \mathrm{S}_{1}=$ fixed effect of stage of lactation ( $1=1$ to 2$) ; \mathrm{C}\left(\mathrm{B}_{\mathrm{j}} \mathrm{P}_{\mathrm{k}} \mathrm{S}_{1}\right)_{\mathrm{m}}=$ random effect of cow ( $\mathrm{m}=1$ to 27$)$ within block, pair, and stage of lactation; $\mathrm{T}_{\mathrm{n}}=$ fixed effect of time $(\mathrm{n}=$ 1 to 2); $\mathrm{T}_{\mathrm{n}} \mathrm{S}_{1}=$ interaction between time and stage of lactation; and $\mathrm{e}_{\mathrm{jklmn}}=$ residual error. Using this model, change in plasma metabolites and insulin and hepatic AcCoA content within stage of lactation were analyzed using the GLIMMIX procedure of SAS and the SLICE option. The Bonferroni adjustment was applied to decrease the probability of type I error when multiple comparisons were done. Pearson correlation coefficients between each variable of interest and DMI at 4 and 24 h by stage of lactation and their $P$-values were obtained using PROC CORR of SAS. Linear and quadratic relationships between DMI at $4 \mathrm{~h}$ and variables of interest by stage of lactation were evaluated by regression.

Using PROC MIXED of SAS, different continuous variables and their interaction with stage of lactation were tested with the following model only to determine if they were related to DMI at $4 \mathrm{~h}$ after feeding:

$$
Y_{j k l}=\mu+B_{j}+P_{k}\left(B_{j}\right)+S_{l}+\operatorname{Var}+\operatorname{Var} \times S_{l}+e_{j k l},
$$

where $Y_{j k l}=$ dependent variable, $\mu=$ overall mean, $B_{j}$ $=$ random effect of block ( $\mathrm{j}=1$ to 3$), \mathrm{P}_{\mathrm{k}}=$ random effect of pair within block ( $\mathrm{k}=1$ to 14$), \mathrm{S}_{1}=$ fixed effect of stage of lactation $(l=1$ to 2$)$, Var $=$ effect of continuous variable, Var $\times \mathrm{S}_{1}=$ interaction between continuous variable and stage of lactation, and $\mathrm{e}_{\mathrm{jkl}}=$ residual error. Normality of the residuals was checked with normal probability and box plots and homogeneity of variances with plots of residuals versus predicted values. Significance was determined at $P \leq 0.05$ for main effects and $P \leq 0.10$ for interactions. Data in Table 2 were expressed as arithmetic means, and data in Table 4 were expressed as least squares means. Data 
Table 2. Characterization of postpartum $(\mathrm{n}=14)$ and late-lactation $(\mathrm{n}=13)$ cows

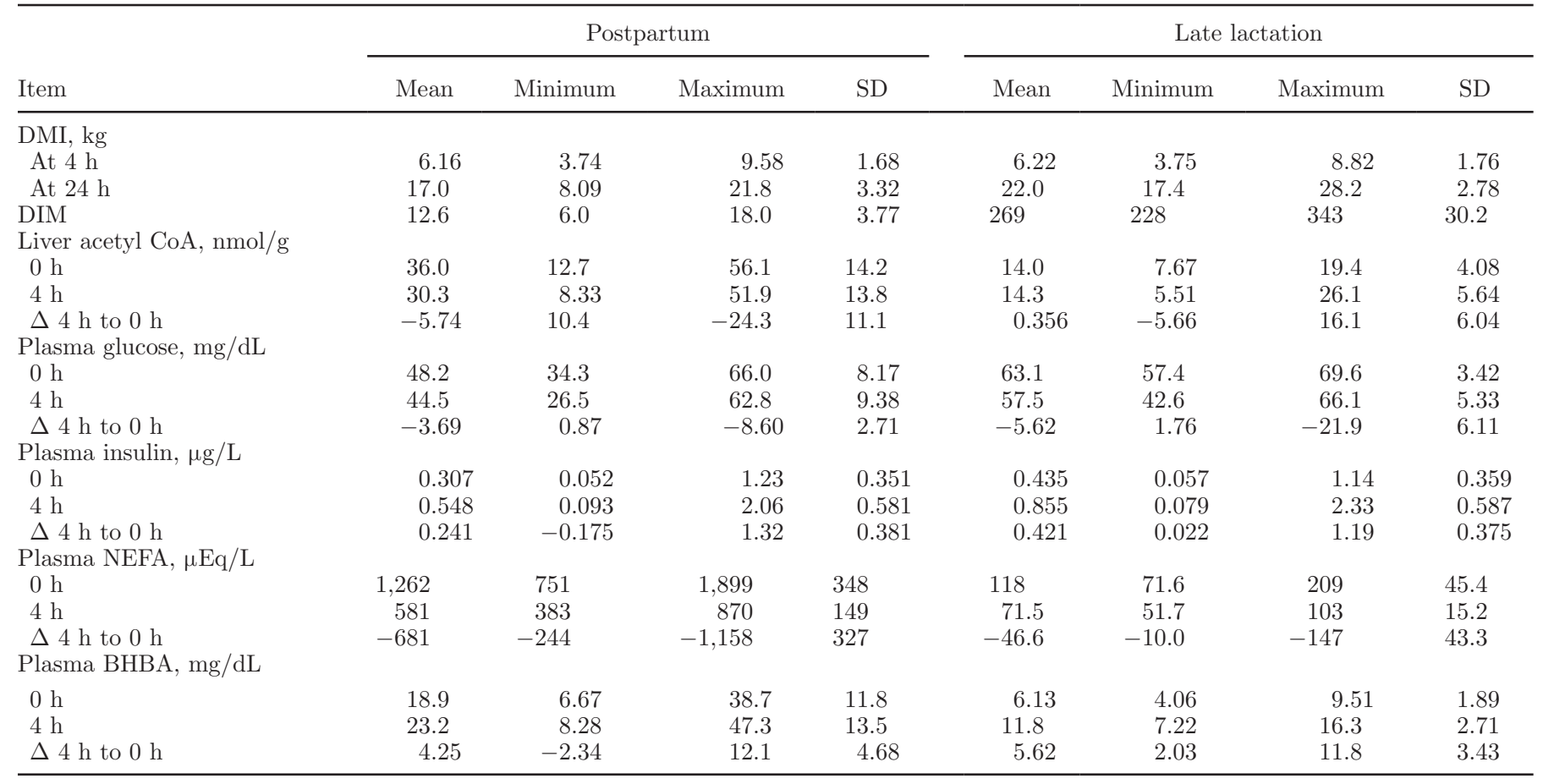

from one LL cow were removed from the analysis because of mastitis. All other cows were in apparent good health throughout the experiment, and their data were included in the analysis.

\section{RESULTS}

\section{Feed Intake in PP and LL Cows}

The range in DIM was 6 to 18 for PP and 228 to 343 for LL cows on biopsy day (Table 2). Feed intake over the 4-h period ranged from 3.7 to $9.6 \mathrm{~kg}$ of $\mathrm{DM}$ in PP cows and 3.8 to $8.8 \mathrm{~kg}$ DM in LL cows, whereas feed intake over the 24-h period ranged from 8.1 to $21.8 \mathrm{~kg}$ in PP cows and 17.4 to $28.2 \mathrm{~kg}$ in LL cows. In general, DMI over $24 \mathrm{~h}$ for both PP and LL cows was not related to variables measured in blood or liver (Table 3). However, DMI at $4 \mathrm{~h}$ was negatively related to the change in hepatic AcCoA $(\mathrm{r}=-0.74 ; P<0.01)$ and plasma NEFA $(\mathrm{r}=-0.61 ; P=0.02)$ in PP cows. In LL cows, DMI at $4 \mathrm{~h}$ was negatively related to the change in hepatic AcCoA $(\mathrm{r}=-0.56 ; P=0.05)$ and the change in plasma glucose $(\mathrm{r}=-0.69 ; P<0.01)$ and NEFA $(\mathrm{r}=-0.62 ; P=0.02)$, but positively related to the change in plasma BHBA $(\mathrm{r}=0.91 ; P<0.0001)$. Plasma NEFA, glucose, BHBA, and insulin concentrations and hepatic AcCoA content before feeding were not related to DMI at $4 \mathrm{~h}$ in PP cows. In LL cows, plas- ma glucose concentration and hepatic AcCoA content before feeding were not related to DMI at $4 \mathrm{~h}$. However, DMI at $4 \mathrm{~h}$ was negatively related to plasma BHBA concentration before feeding $(\mathrm{r}=-0.56 ; P=0.04)$, and tended to be related negatively to plasma insulin concentration before feeding $(\mathrm{r}=-0.48 ; P=0.09)$. In contrast, DMI at $4 \mathrm{~h}$ tended to be related positively to plasma NEFA concentration before feeding for LL cows $(\mathrm{r}=0.49 ; P=0.09)$.

Change in hepatic AcCoA was related to DMI at 4 h overall $\left(P_{\text {Var. }}<0.01\right)$ and did not interact with stage of lactation $\left(P_{\text {Var. } \times \text { Stage }}=0.45\right)$; hepatic AcCoA content at $4 \mathrm{~h}$ interacted with stage of lactation $\left(P_{\mathrm{Var}}=0.03\right.$; $\left.P_{\text {Var. } \times \text { Stage }}=0.02\right)$ as did plasma NEFA before feeding $\left(P_{\text {Var. }}<0.01 ; P_{\text {Var. } \times \text { Stage }}=0.02\right)$ and change in plasma NEFA concentration $\left(P_{\text {Var. }}<0.01 ; P_{\text {Var. } \times \text { Stage }}=0.01\right)$. Other variables tested in the model were hepatic AcCoA content before feeding and plasma NEFA at $4 \mathrm{~h}$, but they did not explain DMI at $4 \mathrm{~h}$.

\section{Hepatic AcCoA and Plasma Metabolites and Insulin Before and $4 \mathrm{~h}$ After Feeding}

Hepatic AcCoA content was higher before and after feeding for PP cows compared with LL cows (31.6 vs. $12.7 \mathrm{nmol} / \mathrm{g} ; P<0.0001)$ and decreased over the first 4 $\mathrm{h}$ after feeding for PP $(28.7$ vs. $34.4 \mathrm{nmol} / \mathrm{g} ; P=0.03$; Table 4) but not for LL cows (interaction $P=0.09$; 
Table 3. Pearson correlation coefficients ( $P$-values in parentheses) between variables measured and DIM and DMI at 4 and $24 \mathrm{~h}$ after feeding in postpartum $(\mathrm{n}=14)$ and late-lactation $(\mathrm{n}=13)$ cows

\begin{tabular}{|c|c|c|c|c|}
\hline \multirow[b]{2}{*}{ Item } & \multicolumn{2}{|c|}{ Postpartum } & \multicolumn{2}{|c|}{ Late lactation } \\
\hline & DMI at $4 \mathrm{~h}$ & DMI at $24 \mathrm{~h}$ & DMI at $4 \mathrm{~h}$ & DMI at $24 \mathrm{~h}$ \\
\hline \multicolumn{5}{|c|}{ Liver acetyl CoA, nmol/g } \\
\hline $0 \mathrm{~h}$ & $0.13(0.66)$ & $0.35(0.22)$ & $-0.13(0.67)$ & $-0.007(0.98)$ \\
\hline $4 \mathrm{~h}$ & $-0.46(0.10)$ & $0.09(0.76)$ & $-0.69(<0.01)$ & $-0.30(0.31)$ \\
\hline $0 \mathrm{~h}$ & $-0.17(0.55)$ & $-0.42(0.13)$ & $0.27(0.36)$ & $0.28(0.35)$ \\
\hline $4 \mathrm{~h}$ & $-0.27(0.35)$ & $-0.39(0.17)$ & $-0.62(0.02)$ & $-0.10(0.75)$ \\
\hline$\Delta 4 \mathrm{~h}$ to $0 \mathrm{~h}$ & $-0.41(0.15)$ & $-0.08(0.79)$ & $-0.69(<0.01)$ & $-0.24(0.42)$ \\
\hline \multicolumn{5}{|c|}{ Plasma insulin, $\mu \mathrm{g} / \mathrm{L}$} \\
\hline $0 \mathrm{~h}$ & $-0.28(0.34)$ & $-0.35(0.21)$ & $-0.48(0.09)$ & $-0.41(0.16)$ \\
\hline $4 \mathrm{~h}$ & $-0.22(0.45)$ & $-0.08(0.77)$ & $-0.40(0.17)$ & $0.004(0.99)$ \\
\hline$\Delta 4 \mathrm{~h}$ to $0 \mathrm{~h}$ & $-0.08(0.78)$ & $-0.20(0.50)$ & $-0.17(0.58)$ & $0.40(0.18)$ \\
\hline $0 \mathrm{~h}$ & $-0.42(0.14)$ & $-0.10(0.74)$ & $-0.56(0.04)$ & $-0.51(0.08)$ \\
\hline $4 \mathrm{~h}$ & $-0.32(0.27)$ & $0.06(0.84)$ & $0.76(<0.01)$ & $0.29(0.34)$ \\
\hline$\Delta 4 \mathrm{~h}$ to $0 \mathrm{~h}$ & $0.14(0.64)$ & $0.42(0.14)$ & $0.91(<0.0001)$ & $0.51(0.08)$ \\
\hline
\end{tabular}

Table 4). The range of change in hepatic AcCoA over the 4-h period was wide for both PP (10.4 to -24.3 $\mathrm{nmol} / \mathrm{g}$ ) and LL (-5.7 to $16.1 \mathrm{nmol} / \mathrm{g}$; Table 2). Plasma NEFA concentrations were higher for PP than for LL cows (923 vs. $96 \mu \mathrm{Eq} / \mathrm{L} ; P<0.01$ ), and decreased during the first $4 \mathrm{~h}$ after feeding for PP (582 vs. 1,263 $\mu \mathrm{Eq} / \mathrm{L} ; P<0.0001$ ) but not for LL cows (interaction $P$ $<0.0001$; Table 4). During the 4 -h period after feeding, plasma glucose concentration decreased for PP (44.6 vs. $48.3 \mathrm{mg} / \mathrm{dL} ; P<0.01)$ and LL cows (57.7 vs. 63.3 $\mathrm{mg} / \mathrm{dL} ; P<0.001)$ while plasma BHBA concentration increased for PP $(23.1 \mathrm{vs} .18 .9 \mathrm{mg} / \mathrm{dL} ; P<0.001)$ and LL cows $(11.7$ vs. $6.0 \mathrm{mg} / \mathrm{dL} ; P<0.0001)$. Four hours after feeding, plasma insulin concentrations increased for both PP (0.55 vs. $0.31 \mu \mathrm{g} / \mathrm{L} ; P=0.03)$ and LL cows (0.86 vs. $0.43 \mu \mathrm{g} / \mathrm{L} ; P<0.001$ ).

\section{Relationship Between DMI at $4 h$ and Change in Hepatic AcCoA Content and Plasma NEFA Concentration}

For PP cows, DMI during the first $4 \mathrm{~h}$ after feeding was positively related to the decrease in hepatic AcCoA content $\left(\mathrm{R}^{2}=0.54 ; P=0.003\right.$; Figure $\left.1 \mathrm{~A}\right)$ and plasma NEFA concentration $\left(\mathrm{R}^{2}=0.38 ; P=0.02\right.$; Figure $\left.1 \mathrm{~B}\right)$. Moreover, the decrease in hepatic AcCoA was positively related to the decrease in plasma NEFA concentration $\left(\mathrm{R}^{2}=0.31 ; P=0.04 ;\right.$ Figure $\left.1 \mathrm{C}\right)$ for PP cows. For LL cows, DMI during the first $4 \mathrm{~h}$ after feeding was also positively related to the decrease in hepatic AcCoA content $\left(\mathrm{R}^{2}=0.31 ; P=0.05\right.$; Figure $\left.1 \mathrm{D}\right)$ and plasma NEFA concentration $\left(\mathrm{R}^{2}=0.38 ; P=0.02\right.$; Figure $\left.1 \mathrm{E}\right)$. However, the change in hepatic AcCoA content was not

Table 4. Hepatic acetyl CoA and plasma variables ${ }^{1}$ measured in postpartum $(\mathrm{n}=14)$ and late-lactation $(\mathrm{n}=13)$ cows before and $4 \mathrm{~h}$ after feeding

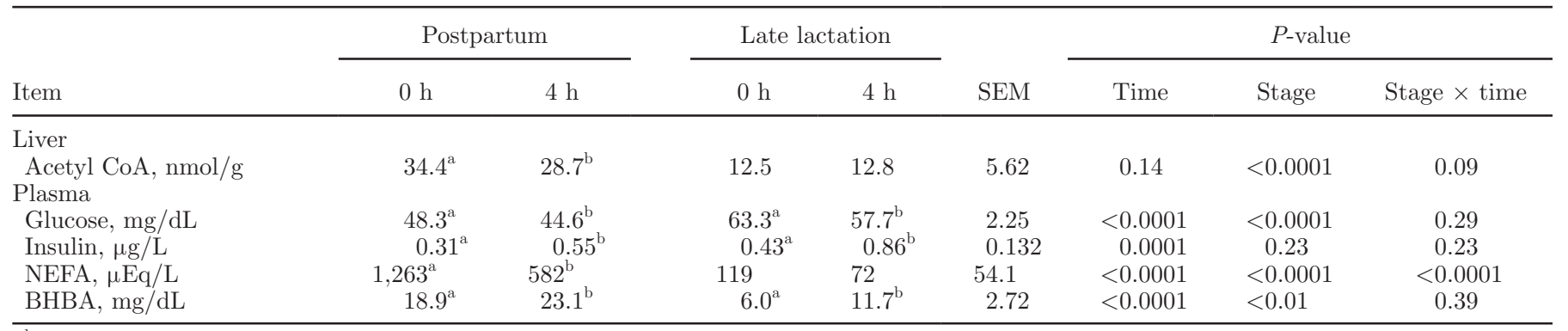

\footnotetext{
${ }^{\mathrm{a}, \mathrm{b}}$ Different superscript letters indicate variables measured were significantly different before and $4 \mathrm{~h}$ after feeding within stage $(P<0.05)$.
}

${ }^{1}$ All values are least squares means. 
A

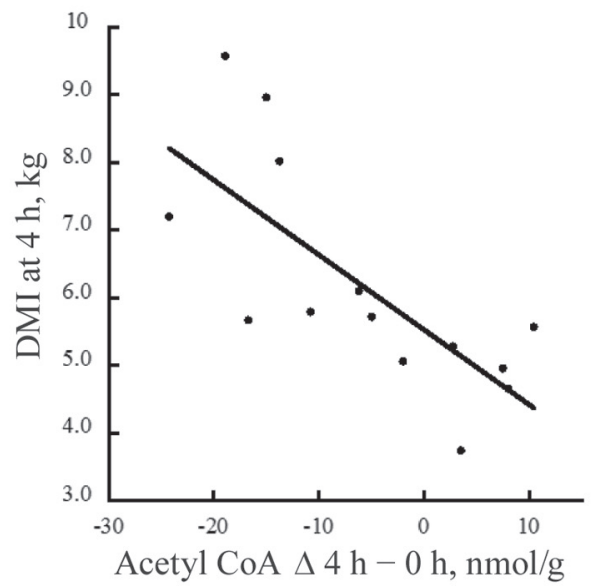

D

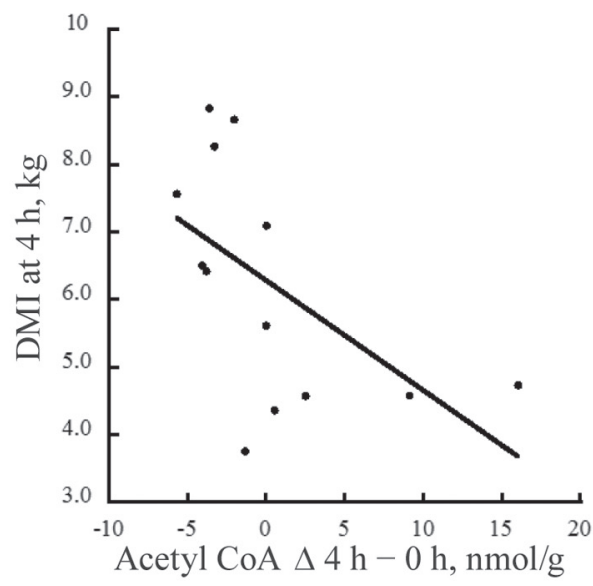

B

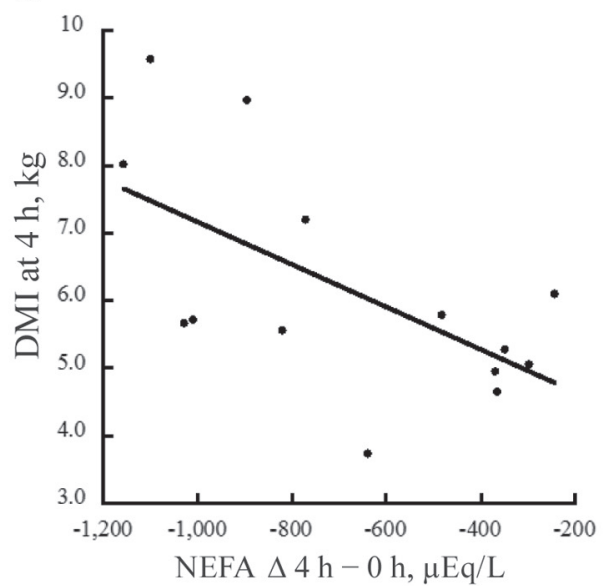

E

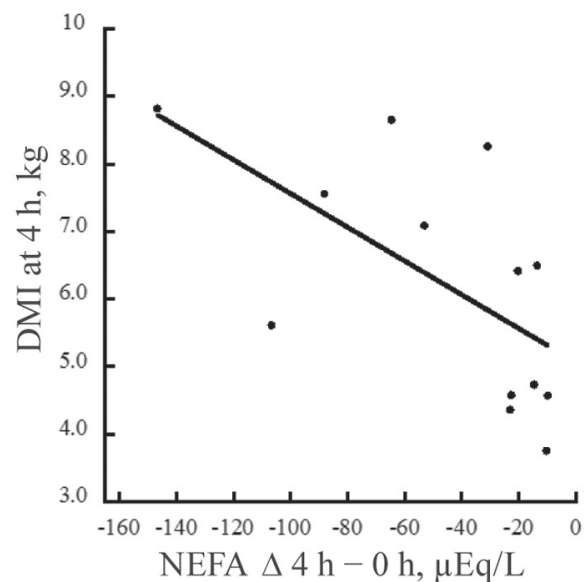

C

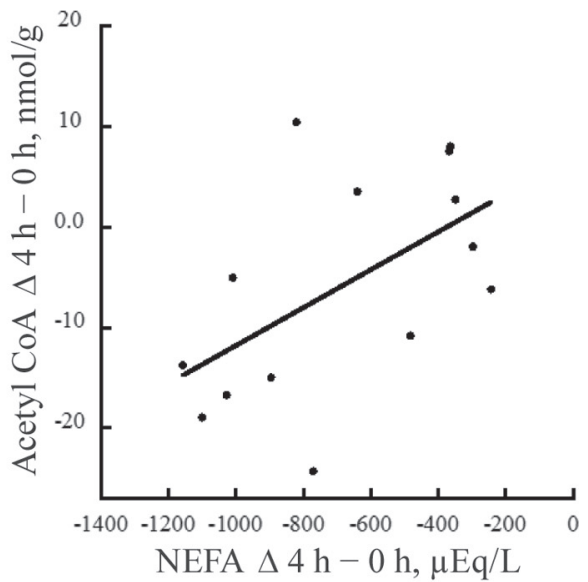

F

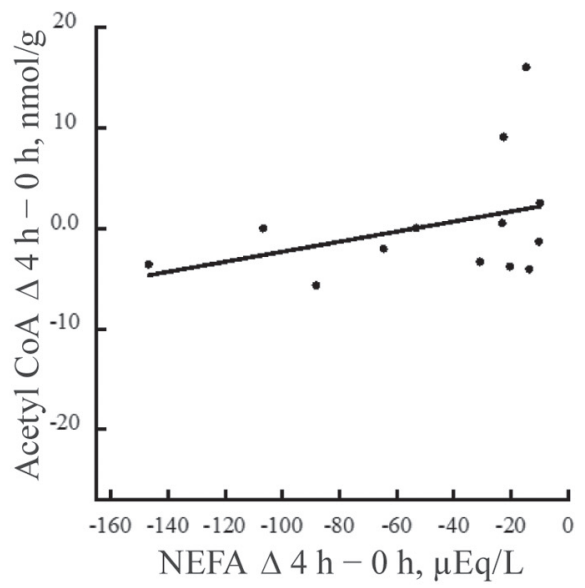

Figure 1. (A) Relationship between change in hepatic acetyl CoA (AcCoA) and DMI at $4 \mathrm{~h}$ in postpartum cows $(\mathrm{PP} ; \mathrm{n}=14 ; \mathrm{AcCoA} \Delta 4 \mathrm{~h}-0 \mathrm{~h}$, $\mathrm{nmol} / \mathrm{g}=24.4-4.89 \times \mathrm{DMI}$ at $4 \mathrm{~h}, \mathrm{~kg} ; \mathrm{R}^{2}=0.54 ; P=0.003$ ). (B) Relationship between change in plasma NEFA concentration and DMI at 4 $\mathrm{h}$ in $\mathrm{PP}$ cows $\left(\mathrm{NEFA}_{\Delta 4 \mathrm{~h}-0 \mathrm{~h}}, \mu \mathrm{Eq} / \mathrm{L}=57.8-120 \times \mathrm{DMI}\right.$ at $\left.4 \mathrm{~h}, \mathrm{~kg} ; \mathrm{R}^{2}=0.38 ; P=0.02\right)$. (C) Relationship between change in hepatic AcCoA

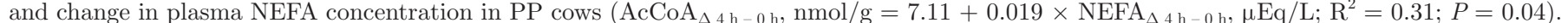
(D) Relationship between change in hepatic AcCoA and DMI at $4 \mathrm{~h}$ in late-lactation cows (LL; $\mathrm{n}=13 ; \mathrm{AcCoA} \Delta 4 \mathrm{~h}-0 \mathrm{~h}, \mathrm{nmol} / \mathrm{g}=12.3-1.92$ $\times \mathrm{DMI}$ at $4 \mathrm{~h}, \mathrm{~kg} ; \mathrm{R}^{2}=0.31 ; P=0.05$ ). (E) Relationship between change in plasma NEFA concentration and DMI at $4 \mathrm{~h}$ in LL cows $(\mathrm{NEFA} \Delta$ $4 \mathrm{~h}-0 \mathrm{~h}, \mu \mathrm{Eq} / \mathrm{L}=47.9-15.2 \times \mathrm{DMI}$ at $\left.4 \mathrm{~h}, \mathrm{~kg} ; \mathrm{R}^{2}=0.38 ; P=0.02\right)$. (F) Relationship between change in hepatic AcCoA and change in plasma NEFA concentration in LL cows $\left(\mathrm{AcCoA}_{\Delta 4 \mathrm{~h}-0 \mathrm{~h}}, \mathrm{nmol} / \mathrm{g}=2.70+0.050 \times \mathrm{NEFA}_{\Delta 4 \mathrm{~h}-0 \mathrm{~h}}, \mu \mathrm{Eq} / \mathrm{L} ; \mathrm{R}^{2}=0.13 ; P=0.23\right)$.

related to the change in plasma NEFA concentration (Figure 1F).

\section{DISCUSSION}

This experiment was conducted to increase our understanding of why propionic acid infused continuously in the rumen for a period of $3 \mathrm{~d}$ decreased DMI only during the first $4 \mathrm{~h}$ after each daily feeding in early-lactation cows, and more so in cows with elevated hepatic AcCoA content (Stocks and Allen, 2013). We also wanted to compare PP with LL cows in terms of hepatic AcCoA and plasma metabolites and insulin because an earlier experiment from our laboratory showed that intraruminal infusions of propionate were more hypophagic in early- than mid-lactation dairy cows (Oba and Allen, 2003). Oba and Allen (2003) proposed that propionate was more hypophagic for cows in the postpartum period that are in a lipolytic state than in mid-lactation cows because the initial pool of hepatic AcCoA available for oxidation is likely higher. However, hepatic AcCoA content was not measured in that experiment. In the current experiment, hepatic AcCoA content before and after feeding was higher for PP than LL cows, consistent with results from Oba and Allen (2003). Moreover, hepatic AcCoA in PP cows decreased after feeding, which might indicate increased oxidation. Nevertheless, greater reductions in $\mathrm{AcCoA}$ were related to higher DMI during the first $4 \mathrm{~h}$ after feeding in both PP and LL cows, which was contrary to our expectation 
if hepatic AcCoA content was reduced by oxidation in the tricarboxylic acid cycle according to the hepatic oxidation theory (Allen et al., 2009). Increased DMI over the first $4 \mathrm{~h}$ after feeding might have been from decreased oxidation of hepatic AcCoA during meals if a reduction in plasma NEFA concentration reduced AcCoA production by $\beta$-oxidation. Consistent with this is that the change in hepatic AcCoA was positively related to the reduction in plasma NEFA concentration for PP cows. In contrast, the change in AcCoA after the 4 -h feeding period was not related to the reduction in plasma NEFA concentration in LL cows, which might indicate that production of $\mathrm{AcCoA}$ from sources other than $\beta$-oxidation is greater in LL cows than in PP cows, which are in a lipolytic state, and therefore, have elevated plasma NEFA concentrations. Interestingly, greater reductions in plasma NEFA concentrations, likely associated with decreased lipolysis after feeding, were positively related to greater intakes for both PP and LL cows, suggesting that decreased $\beta$-oxidation in the liver might allow for higher DMI, consistent with the hepatic oxidation theory (Allen et al., 2009). We included different continuous variables into the statistical model to compare DMI at $4 \mathrm{~h}$ between stages of lactation and found that changes in plasma NEFA concentration and hepatic AcCoA were significant variables. This provides more support to the linear relationships between changes in both NEFA and AcCoA with DMI at $4 \mathrm{~h}$ within stage of lactation. Plasma NEFA concentration in late-lactation cows is usually substantially lower than in postpartum cows, which might explain why NEFA flux to the liver has less of a role in the control of feed intake later in lactation. However, plasma NEFA concentration before feeding tended to be positively correlated with DMI at $4 \mathrm{~h}$ for LL cows. Plasma NEFA concentrations are inversely related to plasma insulin concentrations within a day (Allen, 2014), and plasma insulin concentration increases during and after meals, decreasing lipolysis and plasma NEFA concentrations (Allen et al. 2005). Even though plasma insulin concentration increased and plasma glucose concentration decreased after feeding for both PP and LL cows, plasma NEFA decreased after feeding only for PP cows. However, the change in plasma insulin concentration was not related to the change in plasma NEFA or glucose concentrations across PP or LL cows (all $\mathrm{R}^{2}<0.10 ; P>0.30$; data not shown). This suggests that the decrease in plasma NEFA and glucose concentrations might be related to insulin sensitivity of tissues (not measured) more than to plasma insulin concentration. It is important to note that different diets were fed to PP and LL cows, and therefore, effects of stage of lactation are confounded with diet.
Another explanation for the negative relationship between DMI and change in hepatic AcCoA content, besides lower supply of AcCoA from decreased flux of NEFA to the liver, would be that the oxidation of AcCoA was not related to an increase in hepatic energy charge $\{([\mathrm{ATP}]+1 / 2[\mathrm{ADP}]) /([\mathrm{ATP}]+[\mathrm{ADP}]+$ $[\mathrm{AMP}])\}$. Hepatic energy charge is dependent upon the relative rates of production and utilization of high-energy phosphate bonds, and the rate of utilization might have been greater for cows with higher DMI, that also had higher milk yields $(\mathrm{r}=0.90 ; P<0.0001$; data not shown). Besides oxidation, ketogenesis and hydrolysis of $\mathrm{AcCoA}$ and export as acetate might also decrease the pool of $\mathrm{AcCoA}$ in the liver. In this respect, it has been shown that liver mitochondrial AcCoA hydrolase is activated by NADH and can cleave AcCoA in perfused rat livers, producing acetate concomitantly with ketogenesis, when $\beta$-oxidation of NEFA is enhanced (Yamashita et al., 2001). Production of endogenous acetate has also been shown in vivo in lactating ewes (Costa et al., 1976), and therefore, the cleavage of Ac$\mathrm{CoA}$ and production of endogenous acetate could be an alternative way to deal with high flux of NEFA to the liver in postpartum dairy cattle. Even though greater change in plasma BHBA concentration was related to greater reductions in hepatic AcCoA in LL cows $\left(\mathrm{R}^{2}\right.$ $=0.30 ; P=0.05$; data not shown), increased hepatic ketogenesis is unlikely because we expect this process to decline after feeding, due to a reduction in hepatic acetyl-CoA content, rather than increase. In contrast with LL cows, the change in hepatic AcCoA was not related to change in plasma BHBA in PP cows $\left(\mathrm{R}^{2}<\right.$ $0.01 ; P=0.87$; data not shown). In both PP and LL cows, plasma BHBA concentration increased $4 \mathrm{~h}$ after feeding, and this change was related to DMI at $4 \mathrm{~h}$ in LL but not in PP cows. The increase in rumen production of BHBA from butyrate might have been more evident in LL than in PP cows because of their lower and less variable plasma BHBA concentrations.

In PP cows, DMI during the first $4 \mathrm{~h}$ after feeding was not related to plasma NEFA concentration or any other parameter measured before feeding, indicating that their concentration alone might have little influence on feed intake. In contrast, LL cows with greater DMI during the first $4 \mathrm{~h}$ after feeding tended to have lower plasma insulin and higher plasma NEFA concentrations. Previous research in our laboratory showed that the hypophagic response to a ration containing a more ruminally fermentable starch source was related to plasma insulin concentration (Bradford and Allen, 2007). We suggested that lower gluconeogenic flux for cows with elevated plasma insulin concentration might have increased tricarboxylic acid cycle activity as meals progressed, stimulating ATP production 
and satiety sooner. The lack of a relationship between changes in plasma insulin and NEFA concentrations after feeding across cows might indicate that changes in plasma NEFA were more related to different levels of insulin sensitivity than changes in insulin concentration. Cows in LL with greater DMI during the first $4 \mathrm{~h}$ after feeding also had lower plasma BHBA concentration. However, the hypophagic effect, either central or peripheral, of BHBA remains unclear in the literature. Even though intracerebroventricular infusions of BHBA $(3.6 \mathrm{mmol} / 24 \mathrm{~h})$ have demonstrated to be hypophagic in rats (Arase et al., 1988), elevating plasma BHBA concentration from 0.59 to $1.74 \mathrm{mmol} / \mathrm{L}$ by intravenous infusion had no effect on DMI in lactating cows (Zarrin et al., 2013). Concentrations reached during intracerebroventricular infusions might be higher than those found in cerebrospinal fluid of postpartum cows, so results presented by Arase et al. (1988) might not be physiologically relevant. In a recent study, Laeger et al. (2013) showed that BHBA concentration in cerebrospinal fluid increased after parturition as plasma BHBA increased $(P<0.05)$, but the magnitude of this increase was small compared with plasma BHBA concentration and its correlation with DMI was not reported (Laeger et al., 2013). In addition, BHBA concentration in cerebrospinal fluid did not increase over the first $10 \mathrm{~d}$ postpartum only, when DMI is usually most depressed, but increased from parturition and as lactation progressed through 40 DIM, when DMI typically increases. An association between BHBA concentration in cerebrospinal fluid and DMI could have been suggested if BHBA concentration increased during the peripartum period only and then decreased as lactation progressed, indicating a potential anorectic role of BHBA at the central level. High plasma NEFA concentration before feeding might not always correspond with high hepatic energy charge, because increased $\beta$-oxidation and production of reducing equivalents must be coupled with increased activity of oxidative phosphorylation, which is stimulated by bicarbonate (Acin-Perez et al., 2009). The tricarboxylic acid cycle is the most important source of metabolically generated $\mathrm{CO}_{2}$, and therefore, bicarbonate production increases with anapleurosis during meals, stimulating ATP production from the pool of reducing equivalents, contributing to satiety. Therefore, a reduced cell environment may be temporally uncoupled from ATP production when tricarboxylic acid cycle activity is low.

\section{CONCLUSIONS}

We hypothesized that a greater decrease in hepatic AcCoA will be related to lower DMI during the first 4 $\mathrm{h}$ after feeding assuming the reduction in $\mathrm{AcCoA}$ was from oxidation in the tricarboxylic acid cycle. However, our results indicated the opposite, that a sharper reduction in hepatic AcCoA was related to an increase in DMI for both PP and LL cows. Greater DMI was also related to a decrease in plasma NEFA concentration for both PP and LL cows. Decreased plasma NEFA concentration from increased plasma insulin concentration during meals likely decreased hepatic AcCoA content for oxidation in the liver, allowing greater DMI, consistent with the hepatic oxidation theory. The change in hepatic AcCoA content was related to the change in plasma NEFA concentration in PP but not in LL cows, indicating that sources other than NEFA play more of a role in the control of feed intake by hepatic oxidation of fuels in LL cows compared with PP cows. As expected, hepatic AcCoA was higher in PP than LL cows, and decreased after feeding in PP but not in LL cows. Further research involving production and fate of hepatic AcCoA relative to meals and its relation to hepatic energy status is needed to better understand metabolic control of intake.

\section{ACKNOWLEDGMENTS}

We thank D. G. Main, R. A. Longuski, K. C. Main, and R. E. Kreft (all from Michigan State University) and the staff of the Michigan State University Dairy Cattle Field Laboratory (East Lansing) for their assistance in this experiment as well as Michigan State University AgBioResearch for partial funding of this research.

\section{REFERENCES}

Acin-Perez, R., E. Salazar, M. Kamenetsky, J. Buck, L. R. Levin, and G. Manfredi. 2009. Cyclic AMP produced inside mitochondria regulates oxidative phosphorylation. Cell Metab. 9:265-276.

Allen, M. S. 2000. Effects of diet on short-term regulation of feed intake by lactating dairy cattle. J. Dairy Sci. 83:1598-1624.

Allen, M. S. 2014. Drives and limits to feed intake in ruminants. Anim. Prod. Sci. 54:1513-1524.

Allen, M. S., B. J. Bradford, and K. J. Harvatine. 2005. The cow as a model to study food intake regulation. Annu. Rev. Nutr. 25:523-547.

Allen, M. S., B. J. Bradford, and M. Oba. 2009. BOARD-INVITED REVIEW: The hepatic oxidation theory of the control of feed intake and its application to ruminants. J. Anim. Sci. 87:3317-3334.

Allen, M. S., and P. Piantoni. 2013. Metabolic control of feed intake: Implications for metabolic disease of fresh cows. Vet. Clin. North Am. Food Anim. Pract. 29:279-297.

Arase, K., J. S. Fisler, N. S. Shargill, D. A. York, and G. A. Bray. 1988. Intracerebroventricular infusions of $3-\mathrm{OHB}$ and insulin in a rat model of dietary obesity. Am. J. Physiol. 255:R974-R981.

Benson, J. A., C. Reynolds, P. Aikman, B. Lupoli, and D. Beever. 2002. Effects of abomasal vegetable oil infusion on splanchnic nutrient metabolism in lactating dairy cows. J. Dairy Sci. 85:1804-1814.

Bradford, B. J., and M. S. Allen. 2007. Depression in feed intake by a highly fermentable diet is related to plasma insulin concentration and insulin response to glucose infusion. J. Dairy Sci. 90:38383845 . 
Costa, N. D., G. H. McIntosh, and A. M. Snoswell. 1976. Production of endogenous acetate by the liver in lactating ewes. Aust. J. Biol. Sci. 29:33-42.

Friedman, M. I. 1997. An energy sensor for control of energy intake. Proc. Nutr. Soc. 56:41-50.

Friedman, M. I., R. B. Harris, H. Ji, I. Ramirez, and M. G. Tordoff 1999. Fatty acid oxidation affects food intake by altering hepatic energy status. Am. J. Physiol. 276:R1046-R1053.

Friedman, M. I., M. G. Tordoff, and I. Ramirez. 1986. Integrated metabolic control of food intake. Brain Res. Bull. 17:855-859.

Laeger, T., H. Sauerwein, A. Tuchscherer, O. Bellmann, C. C. Metges, and B. Kuhla. 2013. Concentrations of hormones and metabolites in cerebrospinal fluid and plasma of dairy cows during the periparturient period. J. Dairy Sci. 96:2883-2893.

NRC. 2001. Nutrient Requirements of Dairy Cattle. 7th rev. ed. National Academy of Science, Washington, DC.

Oba, M., and M. S. Allen. 2003. Dose-response effects of intraruminal infusion of propionic acid on feeding behavior of lactating cows in early or midlactation. J. Dairy Sci. 86:2922-2931.

Piantoni, P., A. L. Lock, and M. S. Allen. 2013. Palmitic acid increased yields of milk and milk fat and nutrient digestibility across production level of lactating cows. J. Dairy Sci. 96:7143-7154.
Reynolds, C. K., P. C. Aikman, B. Lupoli, D. J. Humphries, and D. E. Beever. 2003. Splanchnic metabolism of dairy cows during the transition from late gestation through early lactation. J. Dairy Sci. 86:1201-1217.

Stocks, S. E., and M. S. Allen. 2012. Hypophagic effects of propionate increase with elevated hepatic acetyl coenzyme A concentration for cows in the early postpartum period. J. Dairy Sci. 95:3259-3268.

Stocks, S. E., and M. S. Allen. 2013. Hypophagic effects of propionic acid are not attenuated during a 3-day infusion in the early postpartum period in Holstein cows. J. Dairy Sci. 96:4615-4623.

Wildman, E. E., G. M. Jones, P. E. Wagner, R. L. Boman, H. F. Troutt Jr., and T. N. Lesch. 1982. A dairy cow body condition scoring system and its relationship to selected production characteristics. J. Dairy Sci. 65:495-501.

Yamashita, H., T. Kaneyuki, and K. Tagawa. 2001. Production of acetate in the liver and its utilization in peripheral tissues. Biochim. Biophys. Acta 1532:79-87.

Zarrin, M., L. De Matteis, M. C. M. B. Vernay, O. Wellnitz, H. A. van Dorland, and R. M. Bruckmaier. 2013. Long-term elevation of 3-hydroxybutyrate in dairy cows through infusion: Effects on feed intake, milk production, and metabolism. J. Dairy Sci. 96:29602972 